Viso - Cadernos de estética aplicada Revista eletrônica de estética

ISSN 1981-4062

No 18, jan-jun/2016

http://www.revistaviso.com.br/
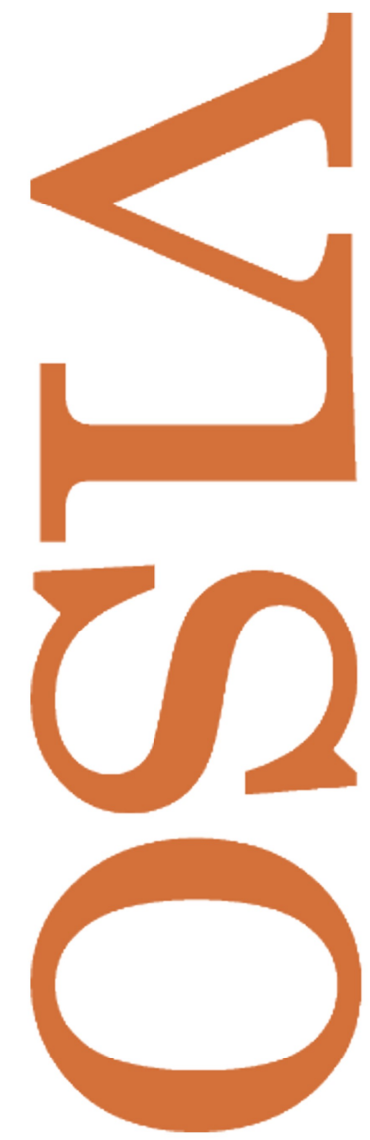

\title{
Intertextualidade, metaficção e autoficção: Fronteiras da narrativa de ficção na literatura do início do século XXI
}

Marcelo de Araujo 


\section{RESUMO}

Intertextualidade, metaficção e autoficção: Fronteiras da narrativa de ficção na literatura do início do século XXI

Na literatura da segunda metade do século XX, existem várias obras em que é explícita a alusão e até mesmo a apropriação de personagens e de ideias de outras obras literárias. Narrativas de ficção que têm como tema a própria produção de narrativas de ficção se tornaram também frequentes na literatura contemporânea. Em algumas obras literárias, a linha que perpassa a fronteira entre a figura do autor e a do narrador se tornou bastante fluida. $\mathrm{O}$ objetivo deste artigo é examinar como algumas obras literárias bem recentes, produzidas nos últimos dez anos, têm levado a intertextualidade, a metaficção, e a autofiç̧ão às últimas consequências. Essas obras, como pretendo mostrar, exploram as fronteiras da literatura com as artes visuais, com o plágio, com relatos autobiográficos, e com o universo de textos publicados sob a forma de postagens nas redes sociais. Em algumas dessas obras, não é sequer evidente se temos diante de nós um "texto", no sentido tradicional da palavra, ou alguma coisa diferente.

Palavras-chave: intertextualidade - metaficção - autoficção - literatura - artes visuais

\section{ABSTRACT}

Intertextuality, Metafiction, and Autofiction: Boundaries of Narrative Fiction in the Literature of Early Twentieth-first-century

In the literature of the second half of the twentieth century the allusion to other literary works, and even the borrowing of ideas and characters from well-known novels, has become frequent. Fiction works in which the very creation of fiction works appears as the main element of the narrative have also become frequent. In some recent literary works the line between fiction and memory is hardly recognizable. This paper aims at examining some recent literary works, produced over the last ten years, in which some writers push intertextuality, metafiction, and autofiction to the limits of narrative fiction. Some of these works defy the boundaries of literature to visual arts, to autobiographies, and the universe of texts posted online in the social networks. In some of these works, it is not even clear whether we still have a text before ourselves, or something else.

Keywords: intertextuality - metafiction - autofiction - literature - visual arts 
ARAUJO, M. de "Intertextualidade, metaficção e autoficção: Fronteiras da narrativa de ficção na literatura do início do século XXI". In: Viso: Cadernos de estética aplicada, v. X, n. 18 (jan-jun/2016), pp. 142161.

DOI: 10.22409/1981-4062/v18i/223

Aprovado: 20.05.2016. Publicado: 03.07.2016.

(C) 2016 Marcelo de Araujo. Esse documento é distribuído nos termos da licença Creative Commons Atribuição-NãoComercial 4.0 Internacional (CC-BY-NC), que permite, exceto para fins comerciais, copiar e redistribuir o material em qualquer formato ou meio, bem como remixá-lo, transformá-lo ou criar a partir dele, desde que seja dado o devido crédito e indicada a licença sob a qual ele foi originalmente publicado.

Licença: http://creativecommons.org/licenses/by-nc/4.0/deed.pt BR

Accepted: 20.05.2016. Published: 03.07.2016.

(C) 2016 Marcelo de Araujo. This document is distributed under the terms of a Creative Commons Attribution-NonCommercial 4.0 International license (CC-BY-NC) which allows, except for commercial purposes, to copy and redistribute the material in any medium or format and to remix, transform, and build upon the material, provided the original work is properly cited and states its license.

License: http://creativecommons.org/licenses/by-nc/4.0/ 


\title{
Introdução
}

Qual é o elemento mais importante na narrativa de um texto de ficção? Já na Antiguidade, Aristóteles dá a essa pergunta uma resposta bastante clara: "o enredo é o princípio, como que a alma da tragédia; em segundo lugar estão os personagens". ${ }^{1}$ A preeminência do enredo (ou plot) é, ainda hoje, bastante presente no tipo de ficção que encontramos em muitos romances, peças de teatro, roteiros para filmes e seriados de TV. Não é por acaso, aliás, que a Poética de Aristóteles se tornou leitura obrigatória em muitos programas de escrita criativa e cursos para a formação de roteiristas. ${ }^{2}$ Muitos autores ainda consideram o enredo a força-motriz da narrativa. É o enredo que coloca os personagens em movimento. É o enredo que garante o encadeamento das ações, que estabelece o desenrolar dos eventos de modo ordenado, e que prende a nossa atenção até o desfecho da história.

No entanto, a partir do século XX, vários escritores começaram a experimentar estruturas narrativas diferentes daquela proposta por Aristóteles na antiguidade. A despeito de toda a influência que a Poética ainda hoje exerce sobre a produção de narrativas de ficção, muitos escritores passaram a questionar a relevância do enredo na estrutura da narrativa. O escritor americano Jonathan Franzen, por exemplo, declarou recentemente numa entrevista o seguinte:

\begin{abstract}
Então, de fato, eu me voltei contra enredos [plot] de modo bem consciente e deliberado ao longo da redação de As correções [2011]. Estruturar o enredo [plotting] é fácil. Eu cresci lendo fiç̧ão científica, fantasia, esse tipo de material pesadamente estruturado [heavily plotted], e esse era meu modo natural, e esse modo era bastante evidente nos dois primeiros romances. Em algum momento quando eu estava estruturando exageradamente [overplotting] As correções eu simplesmente decidi que enredo [plot] é errado. História [story] é realmente simples, história é situacional, e impulsionada pelos personagens, e o enredo começou a me parecer como um obstáculo [contrivance] que estava no caminho. ${ }^{3}$
\end{abstract}

Mas se o enredo deixou de ser o elemento mais importante para a narrativa de ficção em textos literários, que outro elemento então seria esse agora: os personagens; a linguagem; a caracterização do espaço; a representação do tempo? Evidentemente, não há consenso aqui. Alguns escritores às vezes explicam no texto de entrevistas - como Franzen na passagem acima - o que consideram importante na produção de um texto de fiç̧ão. Historiadores da literatura e "críticos literários" também se ocupam dessa questão. É desnecessário mencionar, porém, que nem as entrevistas que os escritores concedem, nem os textos publicados por críticos e historiadores da literatura são textos de ficção. Uma obra de fiç̧ão não se confunde com textos sobre obras de ficção.

No entanto, na literatura do século $X X$, e mais especificamente na literatura da segunda metade do século $X X$, surgiram várias obras de ficção que passaram a ter como tema a própria produção de obras de ficção. Um nome frequentemente usado para falarmos da referência a textos de ficção no interior de outros textos de ficção é "intertextualidade". A 
"intertextualidade", evidentemente, não é uma invenção do século XX, mas ela se tornou indispensável para a compreensão da literatura da segunda metade do século XX. Uma obra de ficção, portanto, pode "falar" sobre outras obras de ficção. ${ }^{4}$

Às vezes, porém, uma obra de ficção pode "falar" sobre obras de ficção sem o recurso à "intertextualidade", sem fazer alusão a outras obras de fiç̧ão já publicadas. Isso ocorre quando um texto de ficção tem como tema a própria produção de um texto de ficção. A narrativa, nesse caso, envolve uma reflexão sobre o que está envolvido na produção de uma narrativa de ficção. Um nome frequentemente usado para nos referirmos a uma narrativa de ficção que tem como tema a produção de uma narrativa de ficção é "metaficção". ${ }^{5}$

Eu afirmei acima que um escritor ou escritora pode tentar explicar em uma entrevista o que ele ou ela pensa sobre a produção de textos literários. O escritor ou escritora pode também falar sobre sua própria obra, esclarecendo questões de influência e aludindo a experiências pessoais que podem ter sido relevantes para a produção da narrativa. Mas o que ele ou ela fala sobre a própria obra não se confunde com a sua obra. O que o escritor ou escritora fala sobre sua própria obra de ficção em uma entrevista não é uma obra de ficção. O "autor" da obra não se confunde com o "narrador" na obra. No entanto, alguns textos de ficção (ou de metaficção nesse caso) se ocupam de tal modo da questão sobre a produção de ficção que nem sempre é inteiramente claro se o texto em questão é, de fato, um texto de ficção, ou se não seria antes um texto não ficcional de um autor de ficção escrevendo sobre a sua experiência com a produção de ficção. Essa confusão entre "autor" e "narrador" é agravada quando o texto de ficção é escrito em primeira pessoa, e tem como protagonista um escritor que, não por acaso, tem o mesmo nome do autor do livro. Um nome frequentemente usado para nos referirmos a um texto de metaficção em que a figura do "narrador" e a figura do "autor" parecem se confundir é "autoficção".

Intertextualidade, metafiç̧ão, e autofiç̧ão se tornaram importantes elementos da narrativa de ficção a partir da segunda metade do século XX. Isso não significa dizer que o enredo não tenha mais importância. Mas o próprio enredo, frequentemente, está subordinado agora à pergunta sobre como a narrativa se relaciona com outras narrativas de ficção. No que se segue, eu gostaria de defender que o elemento mais importante da narrativa de ficção contemporânea é o diálogo com outros textos de ficção. Essa tese, evidentemente, não é nova. A epígrafe que usei no início deste artigo já deixa isso bem claro. ${ }^{6} \mathrm{O}$ que eu gostaria de examinar aqui mais detidamente, porém, é o modo como algumas obras literárias recentes, produzidas nos últimos dez anos, levam a questão da intertextualidade, metaficção, e autoficção às últimas consequências. Na seção $1 \mathrm{eu}$ examino uma obra de ficção bem recente, do escritor e artista multimídia Kabe Wilson, que explora as fronteiras da literatura com as artes visuais. Na seção 2 eu examino um romance recentemente publicado pela escritora e professora de teoria da literatura Cristiane Costa que explora as fronteiras da literatura com o plágio e com a própria 
legibilidade do "texto". Na seção 3, por fim, eu examino algumas passagens de dois escritores - David Foster Wallace e Ricardo Lísias - que exploram as fronteiras da literatura com a memória, com a autobiografia, e com o universo das postagens nas redes sociais.

\section{Retalhando Virginia Woolf}

Em 2014 o escritor e artista multimídia Kabe Wilson concluiu um projeto que the tomou quatro anos de trabalho: criar um imenso anagrama empregando todas as palavras que ocorrem num livro de Virginia Woolf chamado A Room of One's Own (Um Quarto Só Seu), de 1929. O resultado é um painel de 4 metros de comprimento por 1,20 de altura. Wilson recortou e rearranjou as 37.971 palavras utilizadas por Virginia Woolf e criou uma nova narrativa, intitulada Of One Woman Or So (Sobre Uma Mulher, Mais ou Menos), de autoria de uma escritora fictícia chamada Olivia N'Gowfri. Todas as palavras que ocorrem num texto ocorrem também no outro, nenhuma a mais ou a menos. Wilson modificou apenas a pontuação, e o uso de letras maiúsculas e minúsculas. O título do livro e o nome fictício da autora são também anagramas. Isso significa dizer que todas as letras que ocorrem em "Virginia Woolf" também ocorrem em "Olivia N'Gowfri". E todas as letras que ocorrem em "A Room of One's Own" também ocorrem em "Of One Woman Or So". O que Wilson fez, como ele mesmo declara em algumas entrevistas, foi "reciclar" o texto de Virgina Woolf. ${ }^{8}$ Mas a relação entre as duas obras não se limita às palavras que elas têm em comum. A pergunta sobre se poderia existir uma obra "original", desvinculada de um corpus de textos anteriores, é também um dos temas que une os dois autores. Virgina Woolf afirma em $A$ Room of One's Own que obras literárias não são "nascimentos solitários". Ou seja, a produção de novas obras literárias pressupõe a existência de outras obras literárias:

Sem esses precursores, Jane Austen e as irmãs Brontës e George Eliot não poderiam ter escrito mais do que Shakespeare poderia ter escrito sem Marlowe, ou Marlowe sem Chaucer, ou Chaucer sem aqueles poetas esquecidos que abriram o caminho e domaram a selvageria natural da linguagem. Pois obras-primas não são nascimentos solitários isolados; elas são o resultado de muitos anos de pensamento em comum, de pensamento da massa da população, de modo que a experiência da massa esteja por trás da voz singular. ${ }^{9}$

Em uma outra passagem de A Room of One's Own, Virgina Woolf afirma o seguinte: "livros são continuações uns dos outros, apesar de nosso hábito de julgá-los separadamente". ${ }^{10}$ Of One Woman Or So, de Wilson, é a expressão visual dessa ideia. Um texto de fiç̧ão é sempre a "continuação" de outros textos de ficção. Escrever ficção, no fundo, é reordenar palavras, ainda que os leitores - e talvez até mesmo os autores nem sempre se deem conta disso. A proposta de Wilson, e de outros autores contemporâneos, é tornar mais explícito esse de processo "continuação", ou de reordenação criativa de outros textos literários. Mas esse processo, evidentemente, vai 
além da simples reordenação de palavras. Ele se estende também à apropriação de questões que encontramos em obras já publicadas. A questão de que Virgina Woolf se ocupa na obra de 1929 é a seguinte: o que é necessário para que as mulheres possam escrever e publicar ficção? Oitenta anos depois, Wilson se coloca a mesma questão, e propõe uma nova resposta.

A Room of One's Own é um ensaio literário, escrito sob a forma de uma narrativa ficcional, no qual Virginia Woolf trata da dificuldade que as mulheres de sua época enfrentavam para serem reconhecidas como escritoras. Virginia Woolf tomou como ponto de partida de A Room of One's Own uma série de palestras que ela havia proferido em 1928 na Universidade de Cambridge. As palestras foram posteriormente publicadas na revista Forum com o título Mulheres e ficção. ${ }^{11} \mathrm{O}$ livro A Room of One's Own começa com uma pergunta que as pessoas que assistiram às palestras de Virginia Woolf na época devem ter se colocado: "Mas, vocês poderiam dizer, nós pedimos para você falar sobre mulheres e ficção - o que isso tem a ver com ter um quarto só seu?"12 Em inglês, a palavra room significa "quarto", mas num sentido mais geral ela pode significar também "espaço".

Para Virginia Woolf, as mulheres de sua época não dispunham das condições materiais mais elementares para poder produzir textos de fiç̧ão, ou seja: dispor de um quarto individual, em que poderiam trabalhar sossegadas, e dinheiro para poderem se manter. É claro que hoje em dia, mais de oitenta anos depois, seria talvez possível alegar que esse problema já tenha sido resolvido, e que as mulheres já não têm mais de enfrentar nenhuma grande dificuldade para poderem escrever fiç̧ão, e ser reconhecidas como escritoras. No entanto, é justamente essa suposição ingênua que Wilson tenta colocar em questão. Levantamentos recentes mostram que o mercado editorial de língua inglesa ainda é predominantemente representado por escritores do sexo masculino - e brancos..$^{13}$ A situação no Brasil, aliás, não é muito diferente. ${ }^{14}$ Quantas escritoras negras aparecem em listas de best-sellers, são traduzidas para outros idiomas, ou dão entrevistas na TV? Mulheres com uma cor de pele diferente, seja na Inglaterra ou em outras partes do mundo, podem querer reivindicar para si um "espaço próprio" também. Mas, para Virginia Woolf, esse tipo de demanda parece não ter sido um problema relevante na discussão sobre mulheres e ficção. A proposta de Wilson consiste então em "reciclar" o texto de Virginia Woolf de modo a retomar uma questão que não é inteiramente diferente daquela formulada em A Room of One's Own, mas que não ocorreu à autora em 1929. Wilson emprega a mesma linguagem, as mesmas palavras, e o mesmo cenário que encontramos em A Room of One's Own para narrar uma história semelhante, mas a partir de uma perspectiva diferente. O resultado é um diálogo entre várias obras literárias.

Of One Woman Or So conta a história de Olivia N'Gowfri, uma jovem inglesa afrodescendente, lésbica, e insatisfeita com o perfil eurocêntrico e sexista do cânone literário ensinado nos cursos de literatura. A história se passa em outubro de 2009, e começa 


\section{On a night eight hundred years after it was founded the University of Cambridge suffered a great fire, the worst in its remarkable history. though nolone was harmed and property damages jwere, on the whole, fairly minor, the fame of the place was to ensure interest across the world, and the fact that it was Eertainly no accident was to quickly turn this interest into uproas,}

A história narrada em seguida é a das duas semanas que antecedem o incêndio, e das circunstâncias que levaram Olivia N'Gowfri a tentar destruir o cânone literário ocidental. Uma boa parte da trama de Of One Woman Or So gira em torno da palavra "negra" (negress). Segundo Wilson, o uso dessa palavra norteou todo o projeto de "reciclagem".

Há uma passagem de A Room of One's Own na qual Virginia Woolf introduz uma nova personagem: Judith, irmã fictícia de William Shakespeare. Embora Judith não fosse menos talentosa do que o irmão, ela mesma jamais teve a oportunidade de produzir uma obra literária, e de ser aclamada como grande escritora. Afinal, Judith era uma mulher, e mulheres ainda não dispunham de um "espaço próprio" para a produção de ficção no contexto do século XVII. Virginia Woolf sugere que a situação das mulheres, no início do século XX, não era inteiramente diferente. Já havia, é claro, uma tradição de escritoras como Jane Austen, Mary Shelley, as irmãs Brontës, George Eliot (pesudônimo de Mary Ann Evans), etc. Mas é como se todas elas ainda tivessem de se contentar com um quartinho menor, um nicho sem muita importância no meio literário. Virginia Woolf, logo após contrastar o destino trágico de Judith com o sucesso do irmão, afirma então o seguinte: "Uma das grandes vantagens de ser uma mulher é que você pode até passar por uma bela negra [fine negress] sem desejar fazer dela uma inglesa" ${ }^{16}$ Essa frase já foi objeto de muitas interpretações diferentes. ${ }^{17}$ Não é minha intenção me deter aqui no exame dessa discussão. Mas a frase, lida a partir da perspectiva do século XXI, não deixa de sugerir uma posição racista, ou no mínimo eurocêntrica.

No texto Of One Woman Or So, a palavra "negra" adquire uma nova conotação bem mais pejorativa do que em A Room of One's Own. A palavra é usada durante uma festa, para a qual Olivia N'Gowfri havia sido convidada, promovida por uma agremiação de estudantes de literatura chamada "Shakespeare Society". Ao chegar à festa, Olivia N'Gowfri percebe que todos usam a mesma máscara de papel, sobre a qual se vê estampado o rosto de Shakespeare. Na testa, cada máscara ostenta o nome de um escritor ou de algum personagem famoso na história da literatura: Eliot, Voltaire, Milton, Kipling, Tennyson, Sterne, Shelley, Thackery, Keats, Lucydas, Browning, Emily, Marlowe, Bronte, Flaubert, Antigona, Antony, Coleridge, Chaucer, Woodhouse, etc. Todos esses nomes, evidentemente, ocorrem em A Room of One's Own. Mas em Of One Woman Or 
So eles se tornam personagens de um longo diálogo. Para participar da festa e ser acolhida no grupo, Olivia N'Gowfri tem de passar por uma série desafios. O primeiro consiste em recitar a primeira frase do último romance que leu. ${ }^{18}$

\section{'This is the Shakespeare Sociery , known, to the poets and persons in it, as "Shakespeare's ". Fo enter you must tell me the opening sentence of the last novel you read."}

A frase escolhida por Olivia N'Gowfri é "Eles atiraram na garota branca primeiro", do romance Paraíso, da escritora afro-americana Toni Morrison. ${ }^{19}$ Paraíso é conhecido por tratar de relações de gênero e conflitos raciais nos Estados Unidos. Em 1993, Morrison ganhou o Prêmio Nobel de Literatura. Morrison é também autora de uma tese sobre Virginia Woolf. ${ }^{20}$ Seu nome real é Chloe Ardelia Wofford. Esse nome - Chloe - ocorre nove vezes em A Room of One's Own. Em Of One Woman Or So, Chloe é uma mulher pela qual Olivia N'Gowfri parece sentir forte atração. A sequência da narrativa, em que se descreve a participação de Olivia N'Gowfri na festa dos estudantes de literatura, lembra a estrutura de uma peça de teatro.

Olivia N'Gowfri tem de enfrentar seus colegas, mascarados de "escritores" e "personagens", num confronto que envolve perguntas e alusões a romances, citações, trocadilhos literários, aliterações, rimas, e tudo que diga respeito à história da literatura. Para surpresa de todos, Olivia N'Gowfri se mostra culta e perspicaz. Aos poucos, porém, à medida que vão bebendo, os convivas se tornam mais exaltados. Olivia N'Gowfri sugere então que as disputas não se transformem em ataques pessoais. É nesse momento que ela ouve o seguinte comentário: ${ }^{21}$

\section{Browning: Come on, $\mid$ calm down. $6 \mathrm{r} \mid$ do you need grass, negress?}

Nesse contexto, a palavra negress tem uma conotação bem diferente daquela que Virginia Woolf tinha em mente ao escrever A Room of One's Own. A reordenação de palavras, portanto, não é semanticamente neutra. Ela envolve também uma reordenação de sentidos. Ao ouvir a frase de Browning, Olivia N'Gowfri, é claro, se sente ofendida. Ela abandona na mesma hora a festa e começa a compreender melhor a sua própria condição. Por ser mulher, negra, e lésbica ela percebe que jamais terá um "espaço próprio" no meio literário em que circula. Dois eventos marcam então a sequência da narrativa. Um é o encontro de Olivia N'Gowfri com textos de alguns importantes nomes ligados à luta pelos direitos civis dos negros nos Estados Unidos. O outro é o seu encontro com o manuscrito de A Room of One's Own. 
Logo no início de A Room of One's Own, Virginia Woolf dá um nome à sua própria voz: Mary Carmichael. ${ }^{22}$ A personagem Mary Carmichael reaparece no capítulo cinco como autora de uma obra fictícia chamada Life's Adventure. Mas em Of One Woman Or So, Carmichael é o nome de uma outra figura, uma pessoa real: Stokely Carmichael, ativista na luta pelos direitos civis nos Estados Unidos. Carmichael foi um dos expoentes do movimento que ficou conhecido como Black Power. Uma outra figura ligada à luta pelos direitos civis nos Estados Unidos que reaparece em Of One Woman Or So é o ativista $\mathrm{H}$. Rap Brown, autor de Die Nigger Die!: A Political Autobiography, publicado em 1969. Atualmente, Brown cumpre pena de prisão perpétua pela morte de um policial em 2000 no estado do Alabama. Em um discurso de 1967, Brown exortou os estudantes de Cambridge a queimar a cidade, caso as reivindicações pela igualdade de direitos não fossem atendidas. ${ }^{23}$ Mas a cidade em questão, evidentemente, não era a Cambridge de Olivia N'Gowfri, mas uma outra cidade chamada Cambridge, no estado de Massachusetts, nos Estados Unidos. Isso, porém, não impede Olivia N'Gowfri de reordenar geograficamente as palavras de Brown, e de compreender Die Nigger Die! como parte de sua própria biografia. Inspirada então pela leitura dos textos de Brown e Carmichael, Olivia N'Gowfri resolve incendiar a biblioteca da Universidade de Cambridge. Isso ocorre justamente na época em que a biblioteca exibia para o público um clássico da literatura inglesa, um marco no movimento feminista: o manuscrito de $A$ Room of One's Own, de Virginia Woolf.

Olivia N'Gowfri já havia lido A Room of One's Own na tentativa de encontrar uma voz para sua própria insatisfação com o meio literário vigente na Inglaterra. Mas ela acaba considerando o livro de Virginia Woolf bastante elitista, exatamente o oposto do que ela imaginava encontrar. Olivia N'Gowfri começa a acreditar que a literatura, no fundo, serve apenas para perpetuar o tipo de preconceito de que ela própria fora alvo ao dialogar com os "escritores" e "personagens" durante a festa literária. Era preciso agora se vingar, incendiar a biblioteca, destruir a literatura. É assim que o leitor compreende como se deu o incêndio que é mencionado na primeira página da narrativa. Mas, no final, o manuscrito de A Room of One's Own acaba sendo poupado das chamas. Na hora de queimá-lo, Olivia N'Gowfri hesita. Ela resolve então "dar mais uma chance" à escritora. Olivia N'Gowfri decide retalhar o manuscrito, palavra por palavra, e recontar com as mesmas palavras de Virginia Woolf a sua própria versão de "mulheres e ficção" no contexto do século XXI. ${ }^{24}$

\section{'The right words in the right order', who said that? of / poetry ... This is not poetry ... Or truth as I know it ... But, It could be... If I were to mend it ... Cut it up and $\mid$ put them $\mid$ in a different / order ...}

\section{$[\cdots]$}


I will give her another go... I will write her again. For the new now. altering the old "truth". Of what women " are And what "fiction" is .

O texto de Virginia Woolf, "reciclado" por Olivia N'Gowfri, se torna então o manuscrito de Of One Woman Or So. Mas é apenas nas últimas páginas que fica mais claro para o leitor o caráter metaficcional da obra. Of One Woman Or So é uma narrativa sobre como foi produzida a narrativa. $O$ fato de Wilson ter usado as mesmas palavras de Virginia Woolf, para revisitar a mesma questão que a escritora se colocou há mais de oitenta anos, não torna, a meu ver, a sua obra menos "original" do que seria se a nova narrativa não fosse a "reciclagem" de uma obra já publicada. Pelo contrário, a originalidade consiste aqui exatamente nessa "apropriação" criativa que Wilson faz do texto de Virginia Woolf. Obras de ficção não existem isoladas umas das outras, elas não são "nascimentos solitários". Obras de fiç̧ão resultam do reordenamento criativo de outras obras de ficção. E Wilson, a meu ver, leva essa tese às últimas consequências.

É difícil determinar com precisão quando projetos literários desse tipo, em que a narrativa se constrói através da referência explícita à estrutura de outras narrativas, começaram a surgir. A escritora britânica Jean Rhys publicou em 1966, por exemplo, um romance intitulado Wide Sargasso Sea. ${ }^{25}$ Esse romance mantém uma relação estreita com um outro romance: Jane Eyre, de Charlotte Brontë, publicado em 1847. Embora Wide Sargasso Sea tenha sido publicado quase cento e vinte anos após a publicação de Jane Eyre, do ponto de vista da estrutura narrativa formada pelo conjunto das duas obras Jane Eyre é a continuação de Wide Sargasso Sea. ${ }^{26}$ Um texto é a reordenação criativa do outro. Outras expressões podem ser usadas para designar esse tipo de relação entre diferentes obras literárias: reciclagem, apropriação, empréstimo, etc. Evidentemente, Wide Sargasso Sea e Of One Woman Or So não são as únicas obras literárias que tomam de empréstimo elementos de outras obras literárias. Todas as obras literárias fazem isso. Mas é sobretudo na segunda metade do século XX que surge a tentativa de tornar esse processo mais explícito. E em algumas obras literárias mais recentes esse processo de apropriação e reciclagem se torna então, ele próprio, o elemento mais importante da narrativa.

\section{Onde está o sujeito? Quem é o autor?}

Uma escritora brasileira que, a meu ver, foi ainda mais radical na produção de um texto literário que envolve a "apropriação" explícita da produção de outros autores é Cristiane Costa, no livro Sujeito oculto, de 2014. Sujeito oculto é dividido em três partes. A primeira narra a história de um homem tentando descobrir quem era realmente a mulher com a qual fora casado por vários anos, e que acaba de falecer. A narrativa transcorre na primeira pessoa, a partir da perspectiva do marido viúvo. A mulher, ao contrário do marido, gostava muito de literatura, mas ela não era uma escritora original. Ela era 
tradutora. A mulher tinha em casa uma boa biblioteca, mas ela mesma não escreveu quase nada. Quando o marido descobre em casa uma infestação de cupins, e se vê obrigado abrir os livros que a mulher deixou, pela primeira vez ele percebe que a esposa, agora já falecida, tinha o hábito de sublinhar trechos de livros e de transcrever citações em cadernos e agendas. Aos poucos, o marido começa então a traçar um novo perfil da mulher com quem fora casado. Mas esse novo perfil vai surgindo, não como resultado da leitura dos textos que a mulher "escreveu", mas por conta da leitura dos trechos que ela leu, traduziu, e transcreveu. ${ }^{27}$

A segunda parte de Sujeito oculto é ilegível: são vinte e cinco páginas de "texto" tarjado. Evidentemente, podemos nos perguntar se listras pretas no papel, que não contêm sequer vestígios de letras do alfabeto, podem ser chamadas de "texto" e constituir um capítulo de livro. No contexto de Sujeito oculto, porém, não me parece equivocado reconhecermos como "texto" essa parte da obra. A nossa atitude, diante dessas páginas, ainda é a atitude de um leitor ou leitora. Imagine, por exemplo, uma conversa telefônica gravada pela polícia. Antes da divulgação da conversa para a imprensa, a polícia sobrepõe uma parte do diálogo com um ruído que torna impossível para o ouvinte compreender o que está sendo dito. Ainda assim, parece-me que podemos nos referir à gravação como um todo como sendo o registro de uma conversa. O segundo capítulo de Sujeito oculto, a meu ver, constitui um "texto" da mesma forma que o trecho de um diálogo, que a polícia tornou inaudível, continua fazendo parte de uma "conversa". A nossa atitude, tanto num caso como no outro, consiste em encararmos o material na posição de um "ouvinte", ou na situação de um "leitor". O primeiro parágrafo da segunda parte do livro afirma o seguinte:

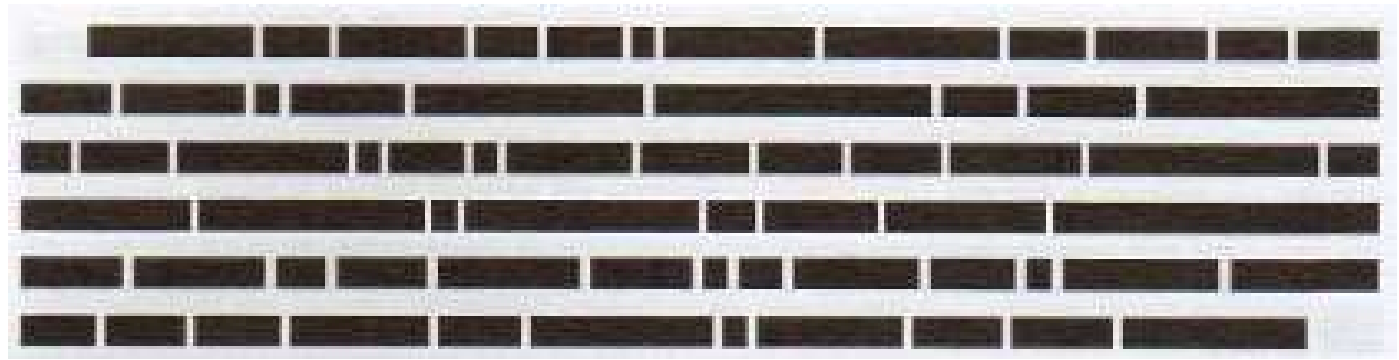

A terceira parte de Sujeito oculto, de Cristiane Costa, é sobre a primeira e a segunda partes de um livro chamado "Sujeito oculto", de autoria de uma escritora fictícia chamada Catarina Guerra. A terceira parte de Sujeito oculto também é narrada em primeira pessoa, mas dessa vez a partir da perspectiva de um crítico literário chamado Julio Paz. Enquanto a primeira parte de Sujeito oculto é narrada em estilo mais coloquial e direto, e a segunda é ilegível, a terceira parte é narrada em estilo mais formal, lembrando a linguagem de um artigo acadêmico, ou tese de doutorado. $O$ narrador da terceira parte esclarece que a segunda parte de "Sujeito oculto" teve de ser inteiramente tarjada porque Catarina Guerra, sua "autora", foi acusada de plágio e processada. ${ }^{29} \mathrm{O}$ narrador 
esclarece ainda que o livro "Sujeito oculto", de Catarina Guerra, foi objeto de uma disputa judicial e proibido de circular com a segunda parte "original". Julio Paz reconstrói então para o leitor a história que era originalmente narrada na segunda parte do livro, e que tinha como título "O amor é sempre inédito". Julio Paz procura também defender Catarina Guerra das alegações de plágio, comparando-a, por exemplo, à escritora alemã Helene Hegemann e ao escritor canadense Yann Martel. Tanto um como outro publicaram recentemente obras em que é notória a apropriação de temas, e até de conteúdo, provenientes de obras. ${ }^{30} \mathrm{O}$ narrador da terceira parte de Sujeito oculto propõe que Catarina Guerra era, na verdade, uma escritora talentosa e original:

Alguns críticos certamente vão discordar, mas lanço a hipótese de que Sujeito oculto não seja exatamente um plágio, mas um livro sobre plagiarismo, que radicaliza a questão da autoria, antecedendo discussões sobre apropriação, remix e mashup que se tornariam correntes nos anos seguintes. ${ }^{31}$

A alusão a textos de outros autores, no livro de Cristiane Costa, não se limita à referência a obras já publicadas. O sobrenome dos dois principais personagens - Catariana Guerra e Julio Paz - parecem também constituir alusões a uma outra obra literária: Guerra e paz, de Tolstói, publicada em 1869. E a figura do crítico literário, que comenta um livro no qual ele mesmo é um personagem, pode talvez ser compreendida como uma alusão a um outro livro de estrutura semelhante: The Pale Fire, de Vladimir Nabokov, publicado em 1962. The Pale Fire contém um poema de 999 versos, supostamente escritos pelo poeta John Shade. O poema é precedido de um "Prefácio", e é acompanhado de um longo comentário e de várias notas explicativas escritas pelo crítico literário ficcional Charles Kinbote. ${ }^{32}$ Tanto em Pale Fire, de Vladimir Nabokov, quanto em Sujeito oculto, de Cristiane Costa, a narrativa da obra consiste, em larga medida, num exame acerca da própria narrativa da obra.

Sujeito oculto tem também um projeto gráfico bastante original: as passagens reproduzidas de outros livros aparecem em cores e fontes diferentes. Mas cabe ao leitor descobrir por si mesmo - talvez com a ajuda do Google - a origem dessas passagens. $\mathrm{O}$ mais interessante no livro de Cristiane Costa, a meu ver, é que nunca fica inteiramente claro quem é o narrador, se é o marido, se é Catarina Guerra, Julio Paz, ou os "verdadeiros" autores das inúmeras passagens transcritas de outros livros. Cristiane Costa assina o livro e, para todos os efeitos jurídicos, ela é sem dúvida a autora da obra. Mas podemos nos perguntar se ainda faz sentido afirmarmos de modo não problemático quem seriam realmente os "autores" e os "narradores" das obras de ficção que lemos. ${ }^{33}$

\section{David Foster Wallace e Ricardo Lísias: narrador ou personagem?}

A indecisão sobre quem é o "narrador", e quem é o "autor", é deliberada em muitas obras da literatura contemporânea, por vezes denominadas "autoficção". O termo "autoficção" foi inicialmente proposto por Serge Doubrovsky. Além de "autoficção", outros nomes são 
por vezes empregados para designar esse tipo de produção literária: "autonarrativa", "escrita de si", "autofabulação", etc. ${ }^{34}$ Nesse tipo de produção literária não é inteiramente claro onde perpassa a linha demarcatória entre ficção, autobiografia, e memória. Seria impossível fazer aqui uma lista exaustiva das obras publicadas recentemente que poderiam ser descritas como obras de "autoficção". ${ }^{35}$ No entanto, há pelo menos uma obra que me parece especialmente expressiva do gênero: O rei pálido (The Pale King), do escritor americano David Foster Wallace.

Foster Wallace se suicidou em 2008. O rei pálido foi publicado postumamente em 2011. O livro, porém, permaneceu inacabado ${ }^{36} \mathrm{O}$ fato de ter permanecido inconcluso seria talvez um problema se $O$ rei pálido tivesse sido originalmente concebido como um livro de enredo tradicional, com um plot que gera no leitor a expectativa de um desfecho consistente. Mas é claro que uma obra de "autofiç̧ão", digna desse nome, evitará a ilusão de desfecho ao final da narrativa. Enquanto se escreve, uma vida é sempre um projeto inconcluso. No capítulo 9 de $O$ rei pálido, Foster Wallace escreve o seguinte:

\section{PREFÁCIO DO AUTOR}

Aqui fala o autor. Ou seja, o autor real, o ser humano a segurar o lápis, não alguma 'persona' narrativa abstrata. Claro, às vezes aparece uma tal persona em O Rei Pálido, mas trata-se apenas de um construto estatutário pro forma, uma entidade que existe apenas para propósito legal e comercial, mais como uma corporação; ela não tem nenhuma conexão direta e demonstrável comigo enquanto pessoa. Mas isto aqui agora sou eu enquanto pessoa real, David Wallace, quarenta anos, número de Segurança Social 975-04-2012, dirigindo-me a vocês [...] neste quinto dia da primavera de 2005, para informar para vocês o seguinte:

Tudo isso aqui é verdade. Este livro é mesmo verídico.

Obviamente eu tenho de explicar. Primeiro, folheie de volta até o início e dê uma olhada no aviso legal [...]: "Os personagens e eventos neste livro são fictícios". Estou ciente de que cidadãos normais quase nunca leem esses avisos legais. [...] Mas dessa vez eu preciso que vocês leiam o aviso legal [disclaimer], e compreendam que essa parte inicial "Os personagens e eventos neste livro..." inclui até mesmo o próprio Prefácio do Autor. Com outras palavras, este Prefácio é definido pelo aviso legal como sendo ele mesmo ficcional, significando isso que ele se situa na área de proteção legal especial estabelecida pelo aviso legal. Eu preciso dessa proteção legal para informar para vocês que o que vem a seguir, na verdade, não é de modo algum ficção, mas substancialmente verdadeiro e acurado. Que O Rei Pálido é, na verdade, mais memórias do que qualquer história inventada. ${ }^{37}$

A pergunta que podemos então nos colocar é a seguinte: quem é o autor do Prefácio de O rei pálido? Foster Wallace, que precisa de proteção legal (disclaimer em inglês) para escrever uma história real disfarçada de ficção, ou Foster Wallace, personagem de Foster Wallace, autor de um livro de ficção em forma de memória? Evidentemente, não há nenhuma resposta objetiva que se possa dar a essa questão. A indecisão sobre se Foster Wallace (o que se matou em 2008) é apenas "autor", ou se ele não seria também 
o "narrador" do livro é, a meu ver, um elemento importante da própria narrativa de O rei pálido e de outras obras de "autofiç̧ão" publicadas nos últimos anos. O disclaimer a que Foster Wallace se refere, e que aparece em quase todas as obras de ficção, é considerado um elemento "pré-textual" do livro. O disclaimer geralmente aparece na mesma página que contém o ISBN da obra, o nome da editora, a cidade e ano de publicação, o nome do revisor, o nome do criador da capa, o nome do tradutor, etc. Em português, o disclaimer pode ter, por exemplo, a seguinte formulação: "Os personagens e situações desta obra são reais apenas no universo da ficção; não se referem a pessoas e fatos concretos, e sobre eles não emitem opinião". ${ }^{38}$ Obras de autofiç̧ão como Rei pálido, portanto, estendem o âmbito da intertextualidade à referência aos elementos "pré-textuais", que integram a obra enquanto produto a ser comercializado no mercado editorial. Mas isso, evidentemente, pode ter implicações judiciais, dependendo da cultura literária e jurídica em que a obra é publicada.

O escritor paulistano Ricardo Lísias, por exemplo, lançou em 2014 uma série de cinco ebooks intitulados Delegado Tobias. ${ }^{39} \mathrm{~A}$ história gira em torno do assassinato de um escritor chamado Ricardo Lísias. O crime é investigado pelo personagem que dá título à série. Ao longo da publicação da série, Ricardo Lísias (o escritor paulistano, e não o personagem assassinado) costumava divulgar parte da trama em seu perfil no Facebook. Em uma das postagens, Lísias anunciou que um certo delegado Paulo Tobias o procurou para dizer que a história narrada em Delegado Tobias era real, e que isso estaria trazendo transtornos à sua vida profissional e pessoal. Lísias chegou mesmo a criar e divulgar online uma ilustração que, para todos os efeitos, tinha toda a aparência de um documento oficial, emitido pela Justiça Federal de São Paulo. O documento fictício constituiria parte de um processo movido pelo delegado Tobias contra Lísias, o autor de Delegado Tobias. Um trecho do "documento" afirma, por exemplo, que o delegado Tobias ordena a imediata suspensão das vendas do e-book, e exige também a "proibição do uso da palavra 'autoficção". Evidentemente, tanto o delegado Tobias, que dá nome à série, como o delegado Tobias, a quem Lísias se refere em seu perfil no Facebook e nos outros volumes da série, são personagens do escritor. Eles não existem de verdade. Eles "são reais apenas no universo da ficção", ainda que o livro de Lísias não seja precedido de um disclaimer que deixe isso explícito para o leitor. O disclaimer, como Foster Wallace enfatiza no "Prefácio" de O rei pálido, "cidadãos normais quase nunca leem". E isso ocorre porque permanece entre o autor e o leitor uma espécie de pacto, um acordo tácito que torna redundante para o leitor ser informado, no verso da segunda folha do livro, que o que virá a seguir é apenas ficção. Contudo, o que algumas obras de metaficção e autoficção recentes propõem é justamente uma revisão dos termos desse acordo, e uma ampliação do universo da intertextualidade.

Obras de metaficção e autoficção, portanto, podem se referir hoje em dia não apenas a outras obras já publicadas, mas também aos elementos pré-textuais do livro, a postagens nas redes sociais, e a documentos ficcionais que podem ter sido criados anteriormente mesmo ao livro como produto a ser comercializado no mercado editorial. 
Esses textos - elementos pré-textuais, postagens na internet, e documentos ficcionais são "externos" à obra, mas eles são também indissociáveis dela. É preciso grifar aqui a palavra "externos" porque textos que só existem como e-books, e que são divulgados por seus autores em redes sociais, fazem parte de um ambiente editorial que vai se ampliando rapidamente: o ambiente dos textos publicados, vendidos, lidos, debatidos e interligados entre si em plataformas digitais na internet. Nesse novo ambiente editorial, nem sempre é inteiramente claro o que é "interno" ou "externo" à obra. ${ }^{40} \mathrm{E}$ isso, a meu ver, confere agora ao fenômeno da "intertextualidade" uma complexidade a mais, que não poderia ter ocorrido aos seus primeiros teóricos da década de 1960. Em uma de suas declarações sobre Delegado Tobias na imprensa, Lísias afirma o seguinte: "Se desse para imprimir, não teria graça. Eu queria que só funcionasse como e-book, com colagens, recortes, perfil (da personagem) no Facebook". ${ }^{41}$

A constatação de que o ambiente editorial em que se produz e se lê ficção em nossos dias já não é mais o mesmo de alguns poucos anos atrás não foi suficiente para impedir que um processo real fosse movido contra Lísias em 2015, por conta de uma suposta falsificação de documentos oficiais. Mas o escritor foi inocentado, e o processo acabou sendo arquivado pelo Ministério Público em abril de 2016. ${ }^{42}$ Durante o inquérito, os leitores podiam acompanhar regularmente o desenrolar das investigações sobre Delegado Tobias a partir do perfil do escritor no Facebook.

Nesse novo ambiente editorial, o fazer literário se torna um empreendimento que envolve a colaboração dos leitores. Os leitores podem agora acompanhar o gradual surgimento de contos e romances em tempo real, e compartilhar com escritores e escritoras suas primeiras impressões. A existência de plataformas digitais como Wattpad tornam ainda mais clara a ideia da produção de narrativa de ficção como um empreendimento coletivo. ${ }^{43}$

\section{Conclusão}

A história da literatura da segunda metade do século $X X$ é marcada pela publicação de diversas obras que, de modo cada vez mais explícito, buscam empreender um diálogo com outras obras literárias. A literatura passa a ter, cada vez mais, o próprio fazer literário como tema. Evidentemente, esse não foi um fenômeno isolado. Na música pop, no cinema, e nas artes visuais, o "empréstimo", a "alusão", e o "remix" de sons, filmes, e imagens é um fenômeno bem conhecido. ${ }^{44} \mathrm{O}$ processo de criação na música, no cinema, e em parte também nas artes visuais é um empreendimento coletivo, pois envolve a colaboração de uma diversidade de profissionais com os quais os créditos pela produção da obra de arte têm de ser compartilhados. Na literatura, porém, ainda persiste por vezes em nossa cultura o mito do escritor como "autor"; do artista que, guiado por uma inspiração literária original, produziria sozinho uma obra. O objetivo deste artigo foi contribuir para a desmistificação dessa ideia, e para o reconhecimento do fazer literário 
como um empreendimento coletivo, e para a caracterização da narrativa de ficção, não tanto como expressão da voz interior do artista, mas como um coral de várias vozes dissonantes, habilmente orquestradas pela mão do escritor.

\section{* Marcelo de Araújo é professor adjunto do Departamento de Filosofia da UERJ.}

1 ARISTÓTELES. Poética, Edição bilíngue grego-português. Tradução de Paulo Pinheiro. São Paulo: Editora 34, p. 83 (capítulo 6, 1450b). A palavra que Aristóteles usa em grego para se referir ao enredo é mythos, mas não no sentido pejorativo que a palavra "mito" passou a ter mais tarde em português e outras línguas modernas.

${ }^{2}$ Ver por exemplo TIERNO, M. Aristotle's Poetics for Screenwriters: Storytelling Secrets from the Greatest Mind in Western Civilization. New York: Hachette Books, 2002; HILTUNEN, A. Aristotle in Hollywood: The Anatomy of Successful Storytelling. Bristol: Intellect, 2001; JAMES, M. "Tragedy, Plot, Fiction: A Study of Sameness and How You May Have Been Duped”. In: New Writing, v. 11, n.1 (2014), pp. 13-24; CLAYTON, S. "Mythic Structure in Screenwriting". In: New Writing, v. 4, n. 3 , pp. 208-223.

3 FRANZEN, J. "First Words on Purity". In: Work in Progress, 2015. Disponível em: http://goo.gl/hcQBeS. O romance As correções, de Jonathan Franzen, foi o vencedor do National Book Award, e do Prêmio James Tait Black Memorial; o romance esteve entre os finalistas para o Prêmio Pulitzer de ficção, e também para o International IMPAC Dublin Literary Award. A obra foi publicada no Brasil pela editora Companhia das Letras, São Paulo, em 2011, com tradução de Sergio Flaksman.

${ }^{4}$ Ver por exemplo ALLEN, G. Intertextuality. Londres, New York: Routledge, 2000; SAMOYAULT, T. A intertextualidade. Tradução de Sandra Nitrini. São Paulo: Aderaldo \& Rotschild, 2008.

${ }^{5}$ WAUGH, P. Metafiction: The Theory and Practice of Self-Conscious Fiction. Londres, New York: Routledge, 1984; MATZ, J. The Modern Novel: A Short Introduction. Oxford: Blackwell, 2004, pp. 134-145; HUTCHESON, L. Narcissistic Narrative: The Metafictional Paradox. Waterloo (Canadá): Wilfrid Laurier University Press, 1980, pp. 36-47; Idem. A Poetics of Postmodernism: History, Theory Fiction. New York, Londres: Routledge, 1988, pp. 105-123.

${ }^{6}$ Ver também por exemplo BARTHES, Roland. "The death of the author". In: Image-Music-Text. Trad. Stephen Heath. New York: Farrar, Straus and Giroux, 1977 [1967], p. 148: "Thus is revealed the total existence of writing: a text is made of multiple writings, drawn from many cultures and entering into mutual relations of dialogue, parody, contestation...". Cf. ALLEN, Graham. "The death of the author". In: Roland Barthes. Londres / New York: Routledge, 2003, p. 63-78.

7 Ver por exemplo FRIEDMAN, S. S. "A Room of One's Own in the World: The Pre-life and the After-life of Shakespeare's Sister". In: BERMAN, J. (org.). A Companion to Virginia Woolf. Hoboken (New Jersey): Wiley-Blackwell, 2016, pp. 189-202; FLOOD, A. "Virginia Woolf's A Room of One's Own Remixed to Form New Story. Kabe Wilson Rearranges Words of Woolf's 1929 Essay to Produce Novella Anagrammatically Entitled Of One Woman Or So." In: The Guardian, 26 de setembro de 2014, disponível em: http://goo.gl/qWFWzw.

${ }^{8}$ WILSON, K. "Olivia N'Gowfri - Of One Woman Or So" [entrevista]. In: Stuart Hall Library, Research Network Symposium, junho de 2013, disponível em: https://goo.gl/i9MTJC. Ver também WILSON, K. "The Dreadlock Hoax" [entrevista], 2014, disponível em: http://goo.gl/fd05Wm.

9 WOOLF, V. A Room of One's Own. Edição organizada por Morag Shiach. Oxford: Oxford University, 2000, pp. 84-85. Texto original em ingles: "Without those forerunners, Jane Austen and the Brontës and George Eliot could no more have written than Shakespeare could have written without Marlowe, or Marlowe without Chaucer, or Chaucer without those forgotten poets who paved the ways and tamed the natural savagery of the tongue. For masterpieces are not single and 
solitary births; they are the outcome of many years of thinking in common, of thinking by the body of the people, so that the experience of the mass is behind the single voice".

${ }^{10}$. Ibidem, p. 104. Texto original em ingles: "For books continue each other, in spite of our habit of judging them separately".

${ }^{11}$ WOOLF, V. "Women and Fiction". In: The Forum (New York), v. 81, n. 3 (mar, 1929), pp. 179-183. Facsimile disponível em: http://goo.gl/QXMgnD.

${ }^{12}$ WOOLF, V. A Room of One's Own. Op. cit., p. 3. Texto original em ingles: "But, you may say, we asked you to speak about women and fiction - what, has that got to do with a room of one's own?"

${ }^{13}$ KEAN, D. Writing the Future: Black and Asian Writers and Publishers in the UK Market Place (relatório). Londres: Spread the Word, 2015; SHUKLA, N. "How Do We Stop UK Publishing Being So Posh and White?". In: The Guardian, 11 de dezembro de 2015. Disponível em http://gu.com/p/4fvf9.

${ }^{14}$ SANTIAGO, A. R. Vozes literárias de escritoras negras. Cruz das Almas (BA): Editora UFRB, 2012. Ver também GEISLER, L. "Luisa Geisler: 'Eu escrevo como mulher, sim': Escritora analisa a escassa presença feminina em prêmios e antologias e aponta machismo no meio literário". In: 0 globo, 22 de novembro de 2014, disponível em: http://goo.gl/mXKnVL; TORRES, B. "Escassez de mulheres no mundo editorial é questionada: Escritoras se fazem menos presentes no topo das premiações e em antologias". In: O globo, 22 de novembro de 2014, disponível em: http://goo.gl/1rMTt6.

${ }^{15}$ WILSON, K. Of One Woman or So. p. 1. Painel com colagem originalmente exposto em Oxford, Bodleian Libraries, em maio de 2015. O texto não foi publicado como livro, mas exibido como obra de arte. As imagens reproduzidas no presente artigo foram gentilmente cedidas pelo autor. Para mais informações sobre a exibição em Oxford, consultar: http://goo.gl/nlahSj. Tradução da passagem citada: "Numa noite, oitocentos anos após ter sido fundada, a Universidade de Cambridge sofreu um grande incêndio, o pior em sua história notável. Embora ninguém tenha se ferido, e danos materiais tenham sido, de modo geral, sem grande importância, a fama do lugar garantiu interesse em todo o mundo, e o fato de certamente não ter sido um acidente rapidamente transformou esse interesse em confusão".

${ }^{16}$ WOOLF, V. Op. cit., p. 65. Texto original em inglês: "It is one of the great advantages of being a woman that one can pass even a very fine negress without wishing to make an Englishwoman of her." Cf. WOOLF, V. "Women and Fiction". Op. cit., p. 181: "In Middlemarch and in Jane Eyre we are conscious not merely of the writer's character, as we are conscious of the character of Charles Dickens, but we are conscious of a woman's presence - of someone resenting the treatment of her sex and pleading for its rights. This brings into women's writing an element which is entirely absent from a man's, unless, indeed, he happens to be a working man, a Negro, or one who for some other reason is conscious of disability".

17 Ver por exemplo MARCUS, J. "A Very Fine Negress". In: Hearts of Darkness: White Women Write Race. New Brunswick (New Jersey): Rutgers University Press, 2004, pp. 24-58; FROULA, C. Virginia Woolf and the Bloomsbury Avant-Garde: War, Civilization, Modernity. New York: Columbia University Press, 2005, pp. 30-32; ZIMMERMAN, T. "The Politics of Writing, Writing Politics: Virginia Woolf's A [Virtual] Room Of One's Own". In: Journal of Feminist Scholarship, v. 3 (2012), pp. 35-55; GARRITY, J. Step-daughters of England: British Women Modernists and the National Imaginary. Manchester: Manchester University Press, 2003, p. 59.

${ }^{18}$ WILSON, K. Op. cit. p. 55. Tradução: "Esta é a Sociedade Shakespeare, conhecida pelos poetas e seus membros como 'de Shakespeare'. Para entrar você deve me dizer a primeira frase do último romance que leu."

${ }^{19}$ MORRISON, T. Paradise. New York: Knopf, 1997: "They shoot the white girl first". O romance foi 
publicado no Brasil pela editora Companhia das Letras, São Paulo, com tradução de José Rubens Siqueira.

${ }^{20}$ WOFFORD, C. A. [MORRISON, T.]. Virginia Woolf's and William Faulkner's Treatment of the Alienated. Ithaca: Cornell University Library, 1955.

${ }^{21}$ WILSON, K. Op. cit., p. 90. Tradução: "Browning: Vamos... acalme-se. Ou você precisa de maconha, sua negra?"

${ }^{22}$ WOOLF, V. Op. cit., p. 5: "Here then was I (call me Mary Beton, Mary Seton, Mary Carmichael or by any name you please - it is not a matter of any importance) sitting on the banks of a river a week or two ago in fine October weather..."

${ }^{23}$ Die Nigger Die! (Morre, Negro, Morre!) não chegou a ser traduzido para o português. Para um relato biográfico curto acerca da participação de Brown na luta pelos direitos civis, ver por exemplo ZAPPA, R; SOTO, E. 1968: Eles só queriam mudar o mundo. Rio de Janeiro: Zahar, pp. 45-46. VINCENT, R. Party Music: The Inside Story of the Black Panthers' Band and How Black Power Transformed Soul Music. Chicago: Chicago Review Press, 2013, p. 100.

${ }^{24}$ WILSON, K. Op. cit., p. 138. Tradução: “'As palavras certas na ordem certa', quem disse isso? Sobre poesia... Isso não é poesia... Ou a verdade, tal como a conheço... Mas, poderia ser... Se eu tivesse de consertar isso... cortar tudo e pôr as palavras numa ordem diferente..." [...] "Eu vou dar a ela uma nova chance... Eu vou escrevê-la novamente. Para o novo agora, alterando a antiga 'verdade'. Sobre o que são as 'mulheres'. E o que é 'ficção'”.

${ }^{25}$ RHYS, J. Vasto mar de sargaços. Tradução de Léa Viveiros de Castro. Rio de Janeiro: Rocco, 2012.

${ }^{26}$ MATZ, J. Op. cit., pp. 138-139 e pp.147-148.

${ }^{27}$ COSTA, C. Sujeito oculto. Rio de Janeiro: Aeroplano, 2014, p. 75: "Acho que só conseguia falar com as palavras dos outros. Não foi à toa que não deixou obra nenhuma, só livros sublinhados e algumas frases e fragmentos soltos. Também não era à toa que passava a maior parte do tempo traduzindo, traduzindo, traduzindo enlouquecidamente para ver algum dinheiro entrar".

${ }^{28}$ Ibidem, p. 75. A segunda parte do livro (pp. 75-100) é inteiramente tarjada.

${ }^{29}$ Ibidem, p. 103.

${ }^{30}$ Yann Martel é autor do livro The Life of Pi (Toronto: Random House, 2001), posteriormente transformado em filme de mesmo nome. Martel foi acusado de plágio, e admitiu ter usado como premissa de The Life of Pi uma resenha que lera do livro Max e os felinos (Porto Alegre: L\&PM, 1981), do escritor brasileiro Moacyr Scliar. Sobre Helene Hegemann, ver por exemplo RAPP, T. "Sex, Drugs and Plagiarism: Did the New Star of German Literature Steal from a Blogger?". In: Der Spiegel Online, 17 de fevereiro de 2010. Disponível em http://goo.gl/O9CeLN

${ }^{31}$ COSTA, C. Op. Cit., p. 105.

${ }^{32}$ NABOKOV, V. Pale Fire. Introdução de Richard Rorty. New York: Vintage Books, 1989 [1962]. Sobre essa obra, consultar BOYD, B. Nabokov's Pale Fire: The Magic of Artistic Discovery. Princeton: Princeton University Press, 1999; BARTH, J. "The Literature of Exhaustion". In: The Friday Book: Essays and Other Non-Fiction. Londres: The John Hopkins University Press, 1984, p. 72; WAUGH, P. Op. cit., p. 85 e p. 103.

${ }^{33}$ Um projeto semelhante ao de Cristiane Costa foi realizado pelo escritor argentino Pablo Katchadjian. Em 2009 Katchadjian reciclou o conto "El aleph", de Jorge Luis Borges, acrescentando cerca de cinco mil palavras ao texto original. O novo texto passou a se chamar "El aleph engordado". A publicação de "El aleph engordado", porém, custou a Katchadjian, em 2015, um processo legal no qual foi acusado de plágio. Cf. SDRIGOTTI, F. "Re-working Borges is a Legitimate Experiment, not a Crime. Argentine Writer Pablo Katchadjian Could Face Jail for Remixing Jorge Luis Borges's story The Aleph - But His is a Thoroughly Borgesian Experiment". In: 
The Guardian, 25 de junho de 2015, disponível em: http://goo.gl/bdGZqp.

34 Ver por exemplo HIDALGO, L. "Autoficção brasileira: Influências francesas, indefinições teóricas”. In: Alea, Rio de Janeiro, v. 15, n. 1 (2013), pp. 218-231.

${ }^{35}$ A "autoficção" se tornou um gênero bastante corrente na literatura brasileira recente. Ver por exemplo: SCOTT, P. O ano em que vivi de literatura. Rio de Janeiro: Foz Impressos e Digitais, 2015; PUJOL, R. Só faltou o título. Rio de Janeiro: Record, 2015; SCHROEDER, C. H. História da chuva. Rio de Janeiro: Record, 2015; MUTARELLI, L. O grifo de Abdera. São Paulo: Companhia das Letras, 2015; LíSIAS, R. Divórcio. Rio de Janeiro: Alfaguara, 2013; SANT'ANNA, S. O livro de Praga. São Paulo: Companhia das Letras, 2011; TEZZA, C. O filho eterno. Rio de Janeiro: Record, 2007. Silviano Santiago, escrevendo em 1984, sugere que a emergência da "narrativa autobiográfica" no Brasil, que não se confunde com a produção "memorialista" dos autores modernistas, coincide com o final do regime militar. Cf. SANTIAGO, S. "Prosa literária atual no Brasil". In: Nas malhas da letra: Ensaios. São Paulo: Companhia das Letras, 1989, pp. 24-37.

${ }^{36}$ Ver MAX, D. T. "The Unfinished David Foster Wallace's Struggle to Surpass Infinite Jest." In: The New Yorker, 9 de março de 2009, disponível em: http://goo.gl/5FbK1T.

${ }^{37}$ O rei pálido, de David Foster Wallace, foi publicado em português pela Quetzal Editores.

${ }^{38}$ Exemplo de disclaimer que aparece em livro de ficção publicado pela editora Companhia das Letras, São Paulo, 2010.

${ }^{39}$ LÍSIAS, R. Delegado Tobias. São Paulo: E-Galáxia, 2014, vol. 1-5.

${ }^{40}$ Ver por exemplo ALLEN, G. "Intertextuality, Hand the World Wide Web". In: Intertextuality. Londres / New York: Routledge, 2000.

${ }^{41}$ RÉGIS, C. "Transitando entre literatura e artes visuais, Ricardo Lísias apresenta livro-inquérito na SP-Arte”. In: Select, 4 de abril de 2016, disponível em: http://goo.gl/W7jcvB.

42 KUSUMOT, M. "Parece ficção: folhetim virtual vira alvo da Polícia Federal". In: Veja, 9 de novembro de 2015, disponível em: http://goo.gl/7c8OC7; RODRIGUES, A. "Obra de ficção cria 'liminar' e vira alvo de investigação da PF". In: Folha de São Paulo, 9 de novembro de 2015, disponível em: http://goo.gl/H6OzAQ; SOBOTA, G. "Livro de Ricardo Lisias leva à instauração de inquérito na Polícia Federal por falsificação de documento". In: Estado de S. Paulo, 11 de setembro de 2015, disponível em: http://goo.gl/H6OzAQ; RODRIGUES, A. "Procurador arquiva investigação sobre 'liminar fictícia' citada em livro". In: Folha de São Paulo, 6 de abril de 2016, disponível em: http://goo.gl/ZJH8IC.

${ }^{43}$ Wattpad: https://www.wattpad.com. Atualmente, muitos escritores e escritoras divulgam seus textos na internet durante o processo mesmo de redação do trabalho. Ver por exemplo STREITFELD, D. "Web Fiction, Serialized and Social". In: New York Times, 23 de março de 2014, disponível em: http://goo.gl/XD281Q. O escritor australiano Max Barry, por exemplo, afirma o seguinte no posfácio de um romance de sua autoria: "Usei muitas ideias de leitores. Não sabia se deveria admitir isso no livro impresso, mas meu respaldo jurídico alega que não se pode ter copyright de ideias, então valeu, otários. Espere. Você não digitou isso, digitou? Ótimo. Porque tem gente que mataria para ter o seu emprego, sabe? Obrigado a todos que me deram ideias, até mesmo as que não usei...". Cf. BARRY, M. Homem-Máquina. Tradução de Fábio Fernandes. Rio de Janeiro: Intrínseca, 2011, p. 283.

${ }^{44}$ Ver por exemplo FERGUSON, K. "Is Everything a Remix?" [vídeo]. TEDTalk, 27 de junho de 2014. disponível em: http://goo.gl/OBXzxb. Cf. Idem "Everything is a Remix" [vídeo documentário]. YouTube, 2013, disponível em: https://goo.gl/dOvUeN. Ver também coletânea de textos incluídos em HARRISON, C.; WOOD, P. (orgs.) "The Critique of Originality". In: Art in Theory: 1900-1990: An Anthology of Changing Ideas. Oxford: Blackwell, 1997, pp. 1049-1085. 